\title{
A Tanzanian Perspective of the Technical Aspects of IT Service Management Education
}

\author{
Jyri Kemppainen \\ University of Eastern Finland, \\ School of Computing, \\ Joensuu, Finland
}

iyri.kemppainen@uef.fi

\author{
Matti Tedre \\ Stockholm University, DSV, \\ Kista, Sweden and \\ Cape Peninsula University of \\ Technology, South Africa
}

matti.tedre@acm.org

\author{
Erkki Sutinen \\ University of Eastern Finland, School of Computing, \\ Joensuu, Finland
}

erkki.sutinen@uef.fi

\section{Executive Summary}

Information technology (IT) professionals face markedly different kinds of challenges in developing countries from the ones in developed countries. Based on the research literature and our fourteen years of fieldwork in Iringa, Tanzania, we have identified eight groups of technical characteristics of IT work that significantly affect the work of IT service management professionals in that particular developing country context. Those groups are climate conditions on the site, physical security on the site, characteristics of premises, characteristics of rooms, quality of electricity, local area network, peripherals, and ICT users.

Even though the characteristics of IT work in developing countries are a challenge for any IT professional, they all can be overcome with appropriate education and preparation. However, scarcity of capable IT professionals who can effectively manage IT systems is an issue in East Africa. Although the situation is widely acknowledged, there are no reports of educational initiatives to address this issue.

We show that without a broad understanding of environmental effects, physical security, powerrelated issues, and characteristics of premises for ICT equipment, IT professionals cannot maintain ICT services of organizations on a sufficient level. Our identified solutions to practical challenges lead us to conclude that IT service management education must include some topics from

Material published as part of this publication, either on-line or in print, is copyrighted by the Informing Science Institute. Permission to make digital or paper copy of part or all of these works for personal or classroom use is granted without fee provided that the copies are not made or distributed for profit or commercial advantage AND that copies 1 ) bear this notice in full and 2) give the full citation on the first page. It is permissible to abstract these works so long as credit is given. To copy in all other cases or to republish or to post on a server or to redistribute to lists requires specific permission and payment of a fee. Contact Publisher@InformingScience.org to request redistribution permission. the fields of electrical engineering and civil engineering in the IT curriculum. Those topics prepare students to overcome context-specific challenges in their future working milieu.

Besides technical topics, organizational support for IT work plays a central role in the self-sustainability of ICT services. Hence, IT professionals should be able to advocate other members of an organi- 
zation. Advocacy work demands good management and communication skills and strong commitment to IT professionalism. Education for IT service management has to recognize these issues and emphasis, in its curriculum design, the role of management and leadership skills in a culturally sensitive way.

Keywords: Information Technology, Technical Support, Curriculum Development, Technology Transfer, ICT for development.

\section{Introduction}

The "appropriate technology" movement emphasizes technological choices that are environmentally friendly and user-centered (Akubue, 2000; Hazeltine \& Bull, 1998). In that movement, people's capacity to master technological solutions is considered to be a central factor for appropriateness of technology in some specific context of use (Hazeltine \& Bull, 1998; Swantz, 1989; Vesisenaho, 2007). We use the term "appropriate" in that broad meaning, and we show that local capability to design, construct, and maintain technical solutions is a core issue in the selfsustainability of information and communication technology (ICT) services. By the term ICT we refer to advanced digital equipment that is used to handle information and/or aid communication. That description is derived from the targets of the World Summit on the Information Society (WSIS) for ICT development until the end of 2015 (e.g., International Telecommunication Union [ITU], 2010). In the WSIS targets, ICT is seen as a tool that allows everyone's participation in the information society (e.g., ITU, 2010, p. 11).

Classification of countries into developed ones and developing ones is not straightforward because stages of development vary between and within all countries. Therefore, the terms "developed country" and "developing country" do not have a single internationally accepted definition. We use the terms "developed countries" and "developing countries" as they are used in the annual Human Development Report of United Nations Development Program (UNDP) (2010). UNDP ranks countries by Human Development Index (HDI) in four categories. Those categories are Very High Human Development, High Human Development, Medium Human Development, and Low Human Development. HDI is combined from statistics for life expectancy, educational attainment, and GDP. The 2010 Human Development Report notes that the countries ranked to category "Very High Human Development” are called "developed countries” and countries in other categories are called "developing countries" (UNDP, 2010, p.26).

Historically speaking, information technology (IT) materialized as an academic discipline much later than IT professionals appeared in workplaces (Association for Computing Machinery, Association for Information Systems, and IEEE Computer Society [ACM/AIS/IEEE-CS], 2005). IT work that supports IT users and organizations in practical utilization of computers was a response to the increasing needs of organizations to utilize personal computers in workplaces in the 1980s. Everyday use of computers required full time professionals who concentrated on developing the necessary IT services. Due to a lack of appropriate IT education, many employees learned their profession through practice instead of through formal education (Association for Computing Machinery, and IEEE Computer Society [ACM/IEEE-CS], 2008). In the 1990s, that educational shortage started to improve when IT educational programs developed. Today, developing countries are undergoing a similar ICT proliferation that developed countries had 20 years ago, and it is important to avoid a similar kind of situation where education does not correspond with the actual needs of organizations.

The institutional goal for IT service management (ITSM) is to assure continuous access to information via ICT (ACM/IEEE-CS, 2008; Adams, Cartlidge, Hanna, Rance, Sowerby, \& Windebank, 2009). This emphasis on information assurance means that IT graduates' work differs from other computing professionals' work because IT professionals have to manage, maintain, and up- 
date IT services instead of just constructing them. The following subsections discuss this viewpoint and show that the design of a technical body of knowledge for ITSM education requires special consideration.

\section{Characteristics of IT Work in Developing Countries}

It has been shown that the characteristics of IT work in developing countries differ greatly from the characteristics of IT work in industrialized countries (Brewer et al., 2006; Kemppainen, 2006; Smillie, 2008; Surana et al., 2008; Tedre, Kemppainen, \& Ngumbuke, 2011; Torero \& Braun, 2006). For example, Brewer et al. (2006, p. 17) showed that the lack of local expertise is a key challenge of ICT infrastructure construction in developing countries. That challenge becomes especially crucial during the maintenance phase of ICT systems when issues such as hardware failures, software infections, and reinstallations materialize. In addition, Brewer et al. (2006, p. 17-21) summarized a number of infrastructural and environmental factors that affect the lifetime of ICT equipment in challenging project contexts. Those factors included issues such as transportation on bumpy roads, seasonal rains, dirt, and dust. The operating specifications of ICT equipment are not entirely realistic for developing regions, either. ICT equipment's maximum operation and non-operation ranges in terms of humidity, heat, ultraviolet exposure, and power fluctuation are too narrow for many developing countries, which significantly reduces the expected lifetime of equipment (Brewer et al. 2006, p. 15).

Similarly, it has been shown that the lack of technical IT expertise is a barrier for economic development of developing countries. For example, Torero and Braun (2006, p. 342) argued that the lack of technical skills is one of the many potential barriers for East African households' as well as small- and medium-scale enterprises' access to ICT. One of the main findings of the study was that in addition to connectivity, utilization of ICT requires local capacity for ICT maintenance and it requires meaningful content for ICT users (Torero \& Braun, 2006, p. 344). Furthermore, a key element for successful utilization of ICT for poverty reduction is the appropriateness of technology for its intended use (Torero \& Braun 2006, p. 164). In addition, when Sachs (2005, p. 233) estimated the economic effects of vocational education in developing regions, he prioritized computer literacy and basic ICT infrastructure maintenance skills.

In addition to the shortage of local expertise, self-sustainability of ICT projects in developing regions is often questioned. For example, Surana et al. (2006, p. 12) noted that the long-term sustainability of transferred ICT solutions is poor in developing countries. They argued that most solutions fail during the piloting phase due to breakdown of components, which results from poor power quality, absence of local expertise, lacking availability to external expertise, and poor ability to predict faults. This notion about failures of ICT projects is not new: as early as the late 1980s, anthropologist Marja-Liisa Swantz (1989) recognized that formerly identified general challenges related to development projects and especially to technology transfer can be found in ICT projects, too. Those challenges were too narrow focus and missing connection to the broader context, which undermined project sustainability. Continuity of external investments was not taken into account when external funding ended, projects were planned on donors' terms and they did not integrate in the needs of societies, and new technology was finally underutilized due to the lack of local skills, indicating dependency on foreign experts. Similarly, Smillie (2008) criticized past efforts to ship technology from industrialized countries to developing ones without emphasizing the local context and people's right to decide on their own development.

As a solution to the current situation where ICT is clearly underutilized in poverty reduction, Heeks (2008, p. 33) presented three goals in the field of ICT for development (ICT4D). Firstly, the people of developing countries should have tools to create digital contents and services. Secondly, the utilization of ICT should create income and jobs. Thirdly, ICT-based innovations should deliver value for the poor. According to Heeks, these challenges demand IT professionals 
who can master computer science, information systems, and development studies. The latest research in the field of human computer interaction (HCI) supports Heeks' argument about the importance of development studies in IT education. For example, Kamppuri (2011) showed that the cultural context of use must be considered carefully during the design phase of cross-cultural ICT projects. Similarly, our own experiences support this standpoint, indicating similar kinds of challenges in other areas of computing, too (Kemppainen, 2006). Still, when one considers Heeks's vision about ICT4D professionals and compares it to the challenges faced during the construction of ICT infrastructure in developing countries, one can argue that Heeks's vision will not succeed without a strong technical foundation. Heeks's vision, where development studies, information systems, and computer science are emphasized in IT education, does not address practical technical challenges that emerge after the implementation phase of ICT projects. Heeks's vision leaves the question about self-sustainability open.

The studies presented above indicate that lack of locally relevant expertise complicates construction of ICT infrastructure in the developing country context. Furthermore, those studies show that, in addition to the challenges during planning and implementation phases of ICT projects, the local stakeholders or beneficiaries are rarely able to master the infrastructure: to operate, maintain, and repair it. Those clear and concrete challenges in the local context of use should be recognized in formal IT education. The following subsection summarizes some of the educational characteristics in higher education of developing countries and analyses contextual choices in IT curriculum development at Tumaini University/Iringa University College (IUCo).

\section{Educational Characteristics of Developing Countries}

The literature does not paint a very promising picture of the quality of education in developing countries. The World Bank Task Force on Higher Education and Society (2000, p. 93-94) stated that higher education contributes very little to economic development of developing countries. Reasons include the quality of education, lack of significant contributions to knowledge, and failure to advance the public interest. The task force recommended improvements to educational infrastructure as well as design, testing, and implementation of new curricula and academic programs. In addition, the task force recommended prioritization of investments in the quality of faculty, science education, and research. More specifically, it has been argued that universities of developing countries have not successfully provided their students with a strong practical understanding of technology (Bass \& Heeks, 2011; Kitchens, 2006). This is due to substandard technical conditions, such as frequent power outages, poor Internet connections, and lack of equipment.

IUCo has acknowledged the importance of local relevance of IT education and commenced a Bachelor of Science (B.Sc.) degree program in IT in 2007, using a contextualized curriculum (Tedre, Bangu, \& Nyagava, 2009; Vesisenaho, 2007). That curriculum was developed in an intensive cooperation of a number of universities. The development was an elaborate and lengthy process, which began in 2000.

The development process of Tumaini's contextual B.Sc. program in IT was anchored in six principles. Those principles are context sensitivity, problem orientation, practicality, interdisciplinarity, international recognition, and basis on research (Tedre et al., 2009). Combined with a number of contextual factors in education, those principles form a complex arrangement, and many aspects of the curriculum have been developed through research. Such aspects include, for example, pedagogical approaches in the program, required level of specialization, emphasis between disciplines and topics. Despite the careful planning, one crucial constraint remains in the B.Sc. program. The program curriculum has to cover a broad range of topics in only three years in order to be both internationally recognized and locally relevant. The available time-three years, as dictated by the national university system - is shorter than the recommended four years in Association for Computing Machinery and IEEE Computer Society's (ACM/IEEE) curricula guidelines 
for undergraduate degree programs in IT (ACM/IEEE-CS, 2008). Furthermore, as a B.Sc. level program, the program does not aim at specialization in any specific branch of IT.

At present, after five years of experience of contextualized IT education on the B.Sc. level, and after the need for higher education has been emphasized nationally (e.g. Tanzanian development vision 2025) as well as locally, IUCo has started a development process for a Master of Science (M.Sc.) degree program in IT. The general structure of Master's degree education differs from that of Bachelor's degree as it aims at specialization (e.g. Coate, 2009). Master's degree programs concentrate on some well-defined areas of study, allowing more advanced concepts to be taught. We have earlier argued that IT education must be based on a deep understanding of the context of IT education, including the resources and strengths of the context, and IT education must respond to the actual needs of each country. Usually that means going beyond the standard IT curricula (Tedre et al., 2009, p. 121). That standpoint created the foundation for the development of M.Sc. degree education as well.

The literature and our own experiences show that IT professionals who work in developing countries need special kinds of technical expertise (Brewer et al., 2006; Iringa University College/Tumaini University [IUCo], 2004; Kitchen, 2006; Surana et al., 2008; Tedre, Kemppainen, et al., 2011; Vesisenaho, 2007). Furthermore, based on our earlier research (Kemppainen, 2006; Tedre et al., 2009), we argue that through specialized education and practical experiences where local context of use is taken into account, IT graduates' achievement level in preventive maintenance rises. Our previous research studies show that when a responsible IT professional pays more attention on the requirements of ICT equipment, surrounding infrastructure, and local physical environment, many hazards can be avoided (Kemppainen, 2006; Tedre et al., 2009). But a focus on contextual issues give rise to two curricular questions: "How should one design an IT curriculum in a way that takes properly into account the local context of use?" and "What kinds of topics should be included in such curriculum?”

After carefully comparing the characteristics of IT work in developing countries with the IT curricula recommendations of ACM (e.g. ACM/AIS/IEEE-CS, 2005; ACM/IEEE-CS, 2008), we argue that availability of information, which is presented as a security service in the information assurance model, should be recognized as a key concept in ITSM education in developing countries. ACM/IEEE's IT curriculum 2008 stated that the protection of organizational data is a crucial aspect of information assurance and a central part of IT graduates' expertise (ACM/IEEE-CS, 2008). The information assurance model that ACM/IEEE presented for educational purposes includes aspects such as availability, integrity, authentication, confidentiality, and non-repudiation (Machonachy, Shou, Ragsdale, \& Welch, 2001). Even though we agree that all the presented aspects are important, we argue that IT professionals in developing countries have to emphasize the availability aspect in their work insofar as their aim is to ensure the usefulness and continuation of organization's ICT services. Even though it is not mentioned in the ACM papers, emphasis of the availability aspect means that IT curriculum has to include locally relevant topics from development studies and engineering. Insufficient education in these professional areas hinders competence of graduates in solving key challenges related to sustainability, scalability, impact of ICT for organizations, and design of appropriate technical solutions in developing countries.

The following section discusses a number of characteristics of IT work in developing countries; characteristics that IT education must explicitly address. Even though the development of a whole curriculum is a multidimensional process, this article concerns technical aspects of that process only. In addition, our approach is pragmatic in the sense that solutions for ongoing problems are valued by their practical consequences. We analyze our data on the special threats that jeopardize the functionality of ICT infrastructure, and we use the Tanzanian context as an example case. Then, we summarize how those threats should be taken into account in ITSM education, and we give a number of practical recommendations for ITSM curricula. Our research data includes re- 
corded field notes, email exchange, research diaries, work calendars, to-do lists, meeting minutes, research studies, and projects' documentations since 1992, when our involvement with IT related development projects in Sub-Sahara Africa began. That data set consists of roughly 9000 pages of records. In addition to our own documentation, the data includes IT coverage in Tanzanian media, visits to a number of IT project sites, and a great number of informal discussions with people who have been involved in IT work in developing countries as teachers, administrators, or project workers.

\section{Example Case: Characteristics of IT Work in Tanzania}

The elements of our analysis—-that is, the immediate world that affects ICT equipment-are portrayed in Figure 1. That world constrains implementation choices, and it poses challenges for IT professionals who design, construct, or maintain ICT services for organizational use. Our analysis assumes that an organization's ICT services rely on its ICT infrastructure. Furthermore, ICT infrastructure depends on reliable and operational ICT equipment. Based on those assumptions, our analysis aims at understanding and eliminating harmful external factors that affect ICT equipment. Those factors are grouped under eight categories: climate conditions on the site, physical security on the site, characteristics of premises, characteristics of rooms, quality of electricity, local area network, peripherals, and ICT users. This categorization arises from our recorded experiences (IUCo, 2004, 2008; Tedre, Apiola, \& Cronje, 2011) as well as supporting literature (e.g. Brewer et al., 2006; Kemppainen, 2006; Smillie, 2008; Surana et al., 2008; Torero \& Braun, 2006), and it is directly reflected in the work of any IT professional who is responsible for ICT services of organizations in developing countries.

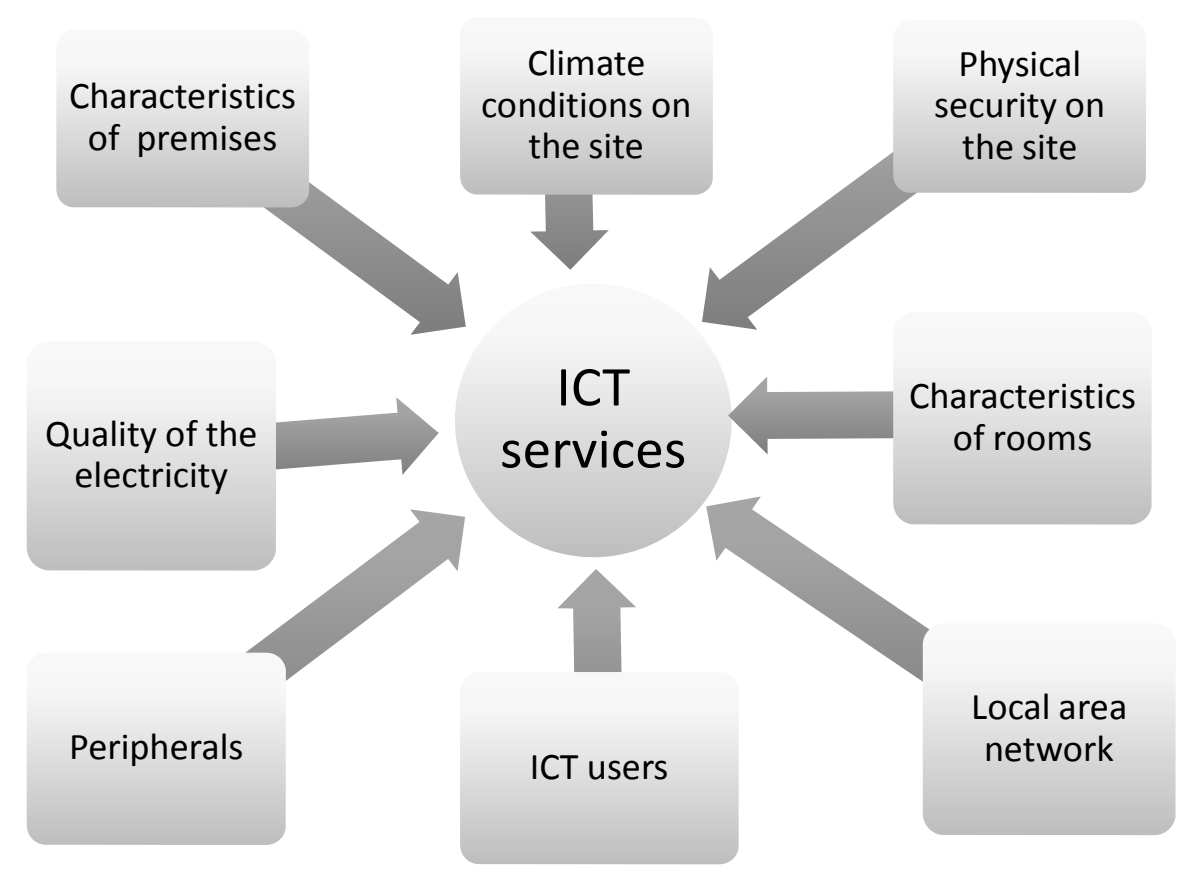

Figure 1: Categorization of external factors that affect ICT services.

The following subsections present and analyze the eight categories Figure 1 in detail. The characteristics that cause indirect effects—such as invitation of tenders, purchase procedures, and delivery logistics - are not presented in this study even though they play a crucial role when the quality of ICT services is evaluated (Tedre, Kemppainen, et al., 2011). For example, delayed delivery of spare parts can seriously hinder the maintenance of ICT infrastructure. 


\section{Climate Conditions on the Site}

Climate conditions pose challenges for IT professionals because ICT equipment is sensitive to various environmental factors. Manufacturers of ICT equipment typically define, for their products, two important ranges for temperature and relative humidity: operating and non-operating range. For example, typical laptop specifications define the operating temperature range to be between +5 and $+35^{\circ} \mathrm{C}\left(+41\right.$ and $\left.+95^{\circ} \mathrm{F}\right)$ and non-operating temperature to be between -20 and $+65^{\circ} \mathrm{C}\left(-4\right.$ and $\left.+149^{\circ} \mathrm{F}\right)$. The operating and non-operating humidity are both typically between $20 \%$ and $80 \%$.

Variations in climate conditions depend on a number of geographical factors such as latitude, distance from the Equator, elevation, proximity to the ocean, and seasonal variation. In our example site Iringa, which is located at mountainous highlands near the Equator (altitude 1600m (5250ft) from the sea level and latitude $7^{\circ} 46^{\prime}$ South from the Equator), the specified temperature range in the shade is rarely exceeded. The temperature in direct sunlight can exceed the operating temperature range (during the dry season in Iringa temperatures as high as $55^{\circ} \mathrm{C}\left(131^{\circ} \mathrm{F}\right)$ have been measured), but as ICT equipment is usually used inside, temperature in direct sunlight rarely causes any issues. Users are usually reluctant to use their equipment in direct sunlight, and wind outside cools the temperature down even if equipment is used outside. However, humidity in Iringa exceeds the typical operating range (20\%-80\%), and in the rainy season humidity has reached $90 \%$. In spite of high humidity, we have not encountered a humidity related failure of equipment during our years in Iringa (IUCo, 2004, 2008; Kemppainen, 2006). However, in the coastal area of Tanzania the situation is quite different. Temperature at the coast is usually over $+30^{\circ} \mathrm{C}$ and humidity typically exceeds $80 \%$. This combination of temperature and humidity has caused travelers' laptops to malfunction in several occasions. When the damage in each case was analyzed, water condensation was recognized on the burned electronic components. Still, the cause for malfunctioning remained uncertain.

The amount of ultraviolet (UV) radiation varies by where the equipment is installed. Especially when equipment such as wireless routers, fiber optic cables or twisted-pair cables are installed in direct sunlight, one should be aware of the effects of UV radiation on plastics. Even though those effects can be ignored when the proper type of products are used or when equipment is located indoors (Hyvönen, 2008), it is our experience that the manufacturers' recommendations often go unnoticed and, for instance, indoor twisted pair cables are used to connect local area networks between buildings, exposed to direct sunlight (Kemppainen, 2006).

Other environmental factors such as dust, wind, rainfall, floods, storms, and earthquakes can partially or completely damage ICT equipment (Brewer et al., 2006; Kemppainen, 2006). Their probability varies greatly even within countries, and their possible impacts on ICT equipment must be considered when constructing ICT infrastructure. For example, in arid areas dust or thin sand can enter equipment casing, which shortens equipment lifetime if ventilation of equipment is not designed properly. These factors are explained more specifically below, in the subsection on characteristics of premises.

Even though recognizing environmental factors is important in the developed world too, in developed countries many of those factors are managed already before the IT professionals' work begins. For example, architects prepare for a number of environmental issues in the architectural designs (e.g., Prospects, 2011). The practical situation in developing countries is different. IT professionals in developing countries have to consider climate conditions when planning, constructing, maintaining, or developing usable ICT infrastructure (Brewer et al., 2006; Kemppainen, 2006). IT professionals should also be able to educate ICT users about the limits of technology, depending on climate conditions in the context of use. 


\section{Physical Security on the Site}

The risk of theft, robbery, and burglary is high in developing countries because the value of ICT equipment is high in terms of the average income in surrounding society (Brewer et al., 2006). The high price of ICT equipment for institutions of developing countries increases the importance of organizational security procedures. Sometimes the financial situation of institution makes it impossible to buy replacements, or at least spending funds on replacements delays the development of other parts of ICT infrastructure (Kemppainen, 2006). In addition, ICT equipment prices are high compared to many other assets, and replacements might not be available locally at all. This means that loss of equipment quickly deteriorates the quality of ICT services in the institution.

The approaches for reducing the risk of theft, robbery and burglary vary, but the typical approach is to improve physical security on the site (Brewer et al., 2006; Kemppainen, 2006). The most common improvements include installing security grilles and a site fence, limiting the number of entrance points, organizing guarding, and preventing unauthorized access to the facilities. Two especially important aspects of guarding are 24/7 coverage and backup support. Burglars rarely arrive alone and it is essential that guards can call in backup support. In addition, all security procedures should have a well-defined monitoring mechanism.

Improved physical security on the site reduces the probability of theft, robbery, and burglary, but it is rarely enough against an inside job, such as participation of some staff members or students in the act (Brewer et al., 2006; Kemppainen, 2006). In our experience, the best response to internal threats is involvement of the whole community (IUco, 2008). In many developing countries, communalism is a more important value than individualism (Farrant, 1981). When the community jointly looks after their facilities, there is little room for thieves to operate (IUCo, 2008).

It is important for IT professionals to understand the opportunities of communalism when planning security measures for ICT equipment in developing countries (Brewer et al., 2006; Kemppainen, 2006). This is especially urgent in educational institutions, where ICT infrastructure is a fundamental tool for learning. The most important method of increasing communal "protection" of ICT equipment is to increase the knowledge of staff and students about the importance of ICT for their work (IUCo, 2008). Firstly, the community should be included in planning ICT development of the institution. Secondly, the surrounding community should gain tangible benefit from the facilities. For example, facilities can be utilized for computer literature courses for the surrounding community.

In conclusion, IT professionals in developing countries require basic understanding about proactive and reactive safety arrangements when they design, implement, and maintain ICT infrastructure. Without the capacity to estimate the adequacy of safety measures or without the capability to advise improvements when necessary, the self-sustainability of ICT services is questionable. In addition to external physical threats, such as theft, burglary, and robbery, IT professionals should have deep understanding about the opportunities of local socio-cultural values and be able to utilize them for minimizing possible internal threats.

\section{Characteristics of Premises}

Characteristics of premises - that is, how well buildings are designed and constructed for ICTrelated operations - affect the construction, use, maintenance, and lifetime of ICT in a number of ways (IUCo, 2008). On the one hand, IT professionals cannot do the work of architects, yet on the other hand, they cannot guarantee the quality of ICT services without basic understanding about those factors. For example, leaking roofs or poorly sealed windows put ICT equipment at risk during the rainy season. Even local fauna may cause unexpected trouble. There are examples 
of rats having chewed cabling, and bees having built nests inside ICT equipment (Kemppainen, 2006).

Proper ventilation arrangements in buildings help to maintain the room temperature within the specified range for ICT equipment (IUCo, 2008; Kemppainen, 2006). For example, in Iringa this means that waterproof roofing is inadequate without a ceiling and proper ventilation between the roof and the ceiling. On a sunny day, corrugated iron roof heats up, heating the air below it. Hence, a ventilated space, an attic, between the roof and the ceiling has to be carefully designed to maximize airflow and minimize heat conduction into the room below. The attic is not crucial in high buildings, such as libraries, where ventilation can be organized using other methods and ICT equipment can be located far below the roofing.

It is also worth mentioning that in growing institutions, which many universities in developing countries are, reallocations of rooms are common (IUCo, 2004, 2008; Kemppainen, 2006). The library may be re-made into a computer hall, a server room into an office, or a computer lab into two smaller labs. Often those changes affect the ventilation dynamics and requirements too; in which case, IT professionals should recognize the changed situation and react accordingly. In addition, old buildings are most likely designed for people only, and their ventilation is insufficient for the heating capacity of computers. Hence, IT professionals must take on an advisory role when new buildings are constructed or old ones are renovated. Our experience is that architects easily underestimate the number of people in ICT facilities at any given moment-take an ICT lab for instance: Some students are working with computers, other students are helping those students, some are queuing for computers, and some are just hanging around (Kemppainen, 2006).

It is still quite common in some developing countries that architectural design does not recognize the requirements of ICT infrastructure (e.g. IUCo, 2004, 2008; North Eastern Diocese of Evangelical Lutheran Church [NED-ELCT], 2008). For example, there might not be enough power sockets or LAN sockets for ICT devices in the offices, classrooms, or laboratories, or those sockets may be in poorly accessible locations. Data projectors require adaptable room lighting, but if there are no curtains, if ceiling windows are too high, or if all the room lights are wired to a single switch, it is not possible to properly adjust the room lights. These issues can also prevent the use of computers during daytime due to difficulties in reading sunlit computer screens.

Very often the installation requirements of LAN wiring are completely ignored during the building construction, leading to their mounting on wall surfaces later (Kemppainen, 2006). In addition, it is common that there is no dedicated space for the buildings' electricity centre, or for shared ICT devices such as server computers, printers, switches, and routers. In such case, shared equipment is typically installed in offices, which hinders maintenance work when offices are in use. We once came across a plan to locate ICT equipment in a storage room that already had car batteries, paints, and other toxic substances. In such situations, IT professionals should even have knowledge about possible chemical reactions that may affect the equipment.

Even if the building plans properly cater to the special requirements of ICT infrastructure, those special requirements may still be neglected during the construction process because of their additional cost. For example, in one project we found that power cabling was changed to a cheaper type, which was designed for lights only, and the cheaper wires were too thin for the power requirements of ICT equipment (Kemppainen, 2006).

The above list is not a comprehensive checklist for evaluating the characteristics of premises from an ICT point of view, but the list indicates some educational needs in IT professional training. Because weaknesses in the design and construction of buildings obviously affect the functioning of ICT equipment, IT professionals must have enough knowledge about building-related constraints when designing well-functioning ICT services. Practically speaking, this means that ICT professionals should be able to understand drawings and electrical diagrams of premises. Similar 
expertise is rarely required in developed countries due to clearer specialization between professions, stricter construction regulations, and supervision by government authorities and private supervisors. Besides training IT professionals to prepare for possible problems due to inappropriate premises, they should also be able to inform the designers and contractors about the special needs of ICT facilities.

\section{Characteristics of Rooms}

Characteristics of rooms and characteristics of premises are closely related, but they are separated here due to two reasons. Firstly, IT professionals require more specific knowledge for analyzing the characteristics of rooms than for analyzing the characteristics of premises. Secondly, changes inside premises, such as reallocation of rooms and renovation jobs, are more common than construction activities. In addition, changes in rooms affect the environment of ICT equipment immediately.

Temperature control might be the most challenging environmental characteristic that concerns a single room (IUCo, 2004, 2008; Kemppainen, 2006). As noted earlier, all ICT equipment have their approved temperature ranges for operation, and keeping the room temperature within those limits demands that the room temperature is properly regulated. The most common method for estimating the required temperature control is to calculate the total heating power in the room. The total heating power depends on the power consumption of all equipment (not just ICT equipment) and the maximum number of people present in the room. The required cooling/heating capacity can be estimated when there is an estimate of the total heating power and ventilation capacity.

It is important to recognize that temperature control and air circulation in rooms are closely related topics (Kemppainen, 2006). In addition, the physical arrangement of ICT equipment and air circulation are, in most cases, closely connected. For example, in order to ensure air circulation, stacking ICT equipment is rarely allowed unless there is some specific minimum space around them.

Even though this section discusses the characteristics of rooms only, it is important to recognize similar considerations when storing equipment in other confined spaces, too-inside vehicles, for example. During the daytime, the temperature rises quickly above the allowed non-operating range in a closed space, such as a car.

Unfortunately, increased ventilation often means increased flow of dust, dirt, and sand (IUCo, 2008). Particle flow must be minimized because as particles build up in cooling and ventilation systems, they reduce the cooling characteristics of ICT equipment. Organized and frequent cleaning of rooms is the first step for reducing the effects of dust, dirt, and sand (Kemppainen, 2006). In some circumstances, incoming air must be filtered. Air filtering is easy to set up if fans or air conditioners are used. Electrical aids to airflow enable also more advanced solutions, such as forcing the room air pressure to be higher than outside. Air pressure difference effectively prevents particles from flowing into rooms via doors, windows, and other entrance points.

Quality of the furniture might be the most untypical issue for IT professionals of developed countries to reflect on (Kemppainen, 2006). However, when one is procuring furniture for ICT purposes in developing countries, quality control saves time and money. One of the main reasons for this is the greatly varying quality of imported products. The quality of imported goods is often poor, which results in a continuous need for replacements and repair. Without careful quality control and planning, local production does not guarantee high quality products either. In one documented case, for example, the weight of two computers and the hands of four students were too much for a computer table, even though the carpenter's work did meet the quality requirements 
(IUCo, 2004). The tensile properties of the chosen material, cypress, were too weak for a table that size.

Effects of other electrical equipment to ICT infrastructure should also be carefully considered. Sometimes electrical equipment, such as motors, speakers, and broadcasting equipment create strong magnetic fields around them, affecting ICT equipment, such as wireless routers and mobile phones. Possibility of magnetic interference can be minimized when the physical arrangement of equipment is carefully planned.

In addition, locations of heavy objects need to be planned carefully. For example, it is not wise to install ICT equipment under ceiling- or wall-mounted water heaters or tanks. Another possible danger for ICT equipment originates from temporary heaters. For example, during the cold season many of our staff warm up their offices using portable heaters. In addition to their high power consumption - which can drop the voltage level in wall sockets or even break voltage protection-the heaters' effects to ICT equipment can rarely be anticipated. Because they are not permanently located in the offices, their heated airflow may be directed to ICT equipment, causing them to overheat.

The number of issues concerning the characteristics of rooms indicates that IT professionals should gain deep knowledge about the cooling principles of ICT equipment and understand the consequences of equipment overheating. In addition, close relationships between temperature control, air circulation, and arrangement of ICT equipment indicate that IT professionals should have enough expertise to analyze possible ICT-related incidents that changes inside the rooms might generate.

\section{Quality of the Electricity}

Aside from strictly IT-related issues, problems with power grid might be the most difficult part of IT professionals' work in developing countries (Brewer et al., 2006; IUCo, 2004; Kemppainen, 2006; Surana et al., 2008). In our analysis, threats to power quality are grouped into two categories based on their origin: general issues and local issues. The sources of threats under the "general issues" category are located outside the institution and are often more difficult to recognize than the threats grouped under the "local issues" category, whose sources are located within the institution.

When analyzing the effect of power quality to ICT equipment, the most important technical aspect to be recognized is the maximum acceptable voltage range of ICT equipment. Some laptops tolerate voltages between 100 Volts and 240 Volts. The permissible range is, however, rarely that broad and most desktop computers, printers, and network equipment obtainable in Tanzania tolerate only 220-240V.

Variations in temperature and humidity levels affect electrical wiring via thermal expansion. This is often the reason for voltage level fluctuations and local power cuts (IUCo, 2004, 2008; Kemppainen, 2006). Variations in temperature loosen the connections where the materials in wire joints differ. Looseness in the joints enables humidity to enter between the connected materials, causing corrosion and increasing resistance. The growing resistance increases the loss of power in the joints, increasing temperature again. Because of this vi-

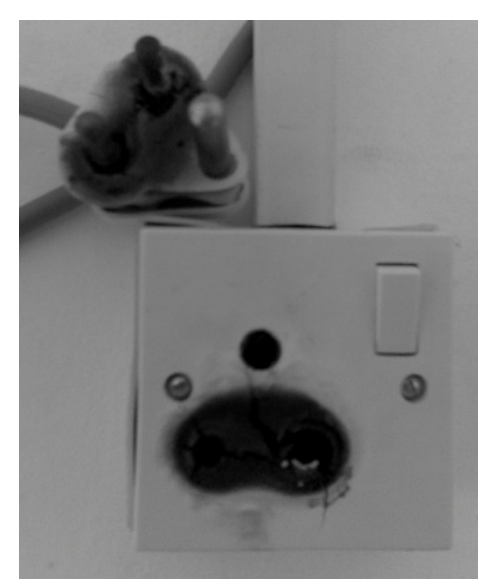

Figure 2: Burned wall socket 
cious circle, voltage level in the wall sockets continuous to drop and finally power is cut due to overheated joints (see Figure 2). For example, because of this problem, IUCo changed more than 300 power sockets in buildings less than six years old in 2002 (IUCo, 2004).

In addition to voltage level fluctuations, variation in temperature and humidity can destroy electrical grounding (Kemppainen, 2006). The quality of grounding is sometimes difficult to measure due to the changing climate conditions. For example, the resistance of wiring may be low in the dry season when humidity is low, while in the rainy season rising humidity increases resistance. In the worst case, grounding may disappear completely due to very high resistance. The importance of good grounding cannot be overly emphasized because it creates the foundation for all protection efforts against high voltage peaks such as lightning strikes. For example, in IUCo's campus, the reason behind the grounding problems is most often the joints, as explained in the previous paragraph, but in some cases, the reason is the grounding (IUCo, 2004). In one case, we measured the resistance between the grounding point and its surrounding soil and found it to be too high. We also recognized that the most probable reason behind the occasional appearance and disappearance of conductivity was changes in soil moisture (IUCo, 2008).

Power source, power supplier, power distribution network, power distributor, and the location of the site form a closely connected network of issues in many developing countries. The main consideration for IT professionals with regard to power is the availability of a reliable power source. The general rule in Tanzania is that spare power sources, typically gasoline or diesel generators, are always required due to regular power cuts and unstable electricity. The main question is often: "Is it possible to construct reliable ICT infrastructure without a major power source on the site or are temporary back-up sources such as small generators and UPS units enough?”

Our study in 2000 showed that during one month at IUCo the line voltage varied between $80 \mathrm{~V}$ and 360V (IUCo, 2004). This variation was measured in normal use situations, not before or after power cuts. In addition to this "normal" variation, there were some voltage peaks that were even higher. The main reason for this large voltage variation was found to be the overloaded local transformer. Power consumption in the suburb was growing quickly without proper communal planning. For instance, many new buildings had been constructed on IUCo's campus, and their wiring was chained from the older buildings. No estimation about their power consumption was done, and the local power company was not aware about the development. The voltage variation notably influenced IUCo's ICT infrastructure. For example, many desktop computers were lost due to overloaded power sources, and basic UPS units lost their batteries due to inadequate protection against high charging voltage (Kemppainen, 2006). In another case, arc welding at our next-door construction site made voltage regulators screech and UPS units beep due to voltage fluctuations. It was learnt that without voltage stabilizers, voltage variation can significantly shorten the lifetime of some types of ICT equipment, such as computer monitors and lamps of data projectors.

Power problems may also result from the work of electricians (Kemppainen, 2006). If electricians are not experienced with the requirements of ICT equipment, they can "solve" ongoing problems in harmful ways. For example, grounding in IUCo's library was once completely disconnected after an electrician had measured $220 \mathrm{~V}$ from it. The present problem was indeed solved but the solution left all ICT equipment without the protective measures based on functional grounding.

The challenges originating from electricity are complex, and a more thorough study would be necessary for getting a full understanding of all aspects of those challenges. In spite of the breadth of this problem area, it is crucial for an organization's ICT services that IT professionals, who are responsible for ICT service management, gain deep knowledge about ICT equipment powerrelated technical requirements. In addition, IT professionals should be able to identify and scien- 
tifically understand such incidents as effects of thermal expansion to power cabling. This means that ITSM education should include appropriate studies about relevant chemistry and physics.

\section{Local Area Network}

Installations of wireless connections are quite similar in developed and developing countries (IUCo, 2004; Kemppainen, 2006; Surana et al., 2008). The incidents noted in the literature, such as frequency collisions, weak signal strengths, and security issues, require similar solutions everywhere. Preventive maintenance of wireless nodes might require special organizational arrangements due to transportation problems, but effects of possible incidents on ICT services can be minimized with carefully planned arrangements such as remote diagnostics.

LAN wiring requires similar kind of special attention as electrical wiring does. The difference between the two types of wiring is that the electric power in LAN wiring is not capable of overheating wire joints or cables. Still, the LAN wiring materials must be chosen as carefully as electrical wiring materials. This is because weak connections in wire joints reduce signal quality, slowing down the transmission speed.

Procuring high quality material for LAN wiring is not always straightforward due to the prevalence of counterfeit products in the developing countries' markets (Tedre, Kemppainen, et al., 2011). In addition, a number of manufacturers dump their low-quality products to developing countries. For example, we bought RJ-45 plugs for IUCo's library, but soon discovered that they were cheap copies of Leviton Telecom's plugs, manufactured in the Far East (IUCo, 2004). Their plastic clips were very fragile and cracked after just a few connections and disconnections.

In addition to careful selection of materials, the contractor should be chosen carefully too (IUCo, 2004; Tedre, Kemppainen, et al., 2011). It is common for "professionals" in developing regions to promise a lot during the competitive bidding, while lacking real expertise for the job. We have recognized that the reference work lists given by the offering companies are the only practical and reliable starting point for comparing contactors' expertise.

In many regions, insects and small animals pose a threat to LAN wiring. As mentioned in the above section on characteristics of premises, their access to buildings must be prevented as effectively as possible. According to our experience, appropriately sealed cable chutes form good protection against these factors (Kemppainen, 2006).

Our experience is that securing organization's ICT services against possible security threats that LAN creates require broader expertise from IT professionals working in developing countries than from those working in developing ones (Tedre, Kemppainen, et al., 2011). This is firstly due to the scarcity of ICT security specialists in developing countries. Due to that reason, IT professionals are rarely able to hire experts from outside the organization. Secondly, commonly used security practices of developed countries often fail when implemented in developing ones. For example, even though the security issues are similar-such as viruses and unauthorized accesses-poor Internet connection might prevent timely download of security updates (IUCo, 2004). Their delivery via postal services might take months, and parcels may get lost on the way.

\section{Peripherals}

Peripherals can create significant threats to other ICT equipment if they are misused or connected improperly (IUCo, 2004; Kemppainen, 2006). For example, a standard USB port cannot deliver more current than $500 \mathrm{~mA}$ (USB 2.0) or $900 \mathrm{~mA}$ (USB 3.0) without overloading. If ICT users are not aware of this maximum load or if the quality of peripherals does not meet international standards - as the case sometimes with counterfeit products is - overloading of USB ports may lead to computer malfunction. The quality of peripherals in developing countries often depends on 
counterfeit products. Unfortunately, various kinds of cheap counterfeit products are commonly traded in the markets of many developing countries, and none can guarantee that they follow industry standards. In addition, it is often time-consuming to estimate the maximum number of peripherals allowed if peripherals' technical specifications are imprecise, or if those specifications are downloadable from web sites only. Therefore, it is necessary that IT professionals are able to advise and educate users about peripheral-related technical issues.

In some special circumstances, knowledge about internal wiring of ICT equipment is crucial. For example, an ill-conceived peripheral may bridge electrical problems between ICT equipment via grounding (Kemppainen, 2006). This can occur when the zero and grounding wires are internally connected in some of the peripherals. These kinds of situations are avoidable via careful location planning for ICT devices.

\section{ICT Users}

The use of ICT equipment in unintended ways is often the cause of incidents in ICT services. Hence, continuous user training is a key factor for successful utilization of ICT services in organizations (Kemppainen, 2006). For example, the probability of file system corruption and loss of information is high when ICT users ignore proper shutdown procedures. Sometimes users simply ignore virus warnings when they move files between computers. These kinds of user-derived incidents indicate a lack of basic ICT literacy. The solution is simple: ICT education. That education should not underestimate users' attitudes. Attitude changes are especially crucial when computers are connected to the Internet. For example, it seems to be very difficult for the majority of new ICT users to answer "no" to any kind of question appearing on the screen during an Internet search.

IT professionals have to carefully consider the extent of users' ICT knowledge because in addition to normal ICT education (such as how to use the word processor), users need up-to-date understanding about the current service level of in-house ICT infrastructure and the organization's ICT policies (Adams et al., 2009; Bon, Pieper, \& Veen, 2006). ICT users should also be familiar with and committed to commonly agreed procedures when special situations arise, such as equipment failures or needs to install new software. Site planning is also a crucial element for minimizing the number of user-related incidents. For instance, the users' need to frequently move ICT equipment between separate locations can be minimized by recognizing ergonomics already during the planning phase. There again, temptation to steal small components such as memory chips or mice is minimized when the risk of getting caught is high.

\section{Necessary Technical Body of Knowledge}

Table 1 summarizes our analysis about the possible external factors affecting ICT services presented in the section Example Case-Characteristics of IT Work in Tanzania. It is important to recognize that Table 1 presents only locally relevant technical topics, not the whole body of knowledge for a M.Sc. degree. The first column of Table 1 summarizes the locally significant technical knowledge areas for ITSM education. The second column of the table summarizes corresponding practical skills necessary for IT students to learn. 
Table 1: Knowledge areas and corresponding skills

\begin{tabular}{|c|c|}
\hline Knowledge areas & Corresponding skills \\
\hline \multicolumn{2}{|c|}{ Climate conditions on the site: } \\
\hline \multirow{3}{*}{$\begin{array}{l}\text { Operating and non-Operating ranges of } \\
\text { ICT equipment } \\
\text { Effects of UV radiation to equipment } \\
\text { Local climate conditions }\end{array}$} & $\begin{array}{l}\text { To evaluate and minimize the possible effects of } \\
\text { local climate conditions to ICT infrastructure }\end{array}$ \\
\hline & To ensure safe operating and non-operating envi- \\
\hline & ronment for ICT equipment \\
\hline \multicolumn{2}{|c|}{ Physical security on the site: } \\
\hline \multirow{3}{*}{$\begin{array}{l}\text { Security arrangements } \\
\text { Cultural issues } \\
\text { Security procedures }\end{array}$} & To evaluate requirements for physical security \\
\hline & arrangements related to ICT services \\
\hline & $\begin{array}{l}\text { To advise and negotiate practical improvements } \\
\text { when weaknesses in security arrangements might } \\
\text { threaten the quality or continuity of ICT services }\end{array}$ \\
\hline \multicolumn{2}{|c|}{ Characteristics of premises: } \\
\hline \multirow{2}{*}{$\begin{array}{l}\text { Technical characteristics of buildings (e.g. } \\
\text { internal threats, such as power issues, and } \\
\text { external threats such as insects and small } \\
\text { animals) }\end{array}$} & $\begin{array}{l}\text { To analyze drawings and electrical diagrams of } \\
\text { premises from viewpoint of ICT services }\end{array}$ \\
\hline & $\begin{array}{l}\text { To design and protect ICT infrastructure with ap- } \\
\text { propriate technical solutions }\end{array}$ \\
\hline \multicolumn{2}{|c|}{ Characteristics of rooms: } \\
\hline \multirow{2}{*}{$\begin{array}{l}\text { Characteristics of ICT equipment in their } \\
\text { context of use (e.g. temperature ranges, } \\
\text { furnishing, electromagnetic interference) }\end{array}$} & $\begin{array}{l}\text { To plan placement, install, and protect ICT } \\
\text { equipment according to their specifications }\end{array}$ \\
\hline & $\begin{array}{l}\text { To document necessary requirements of ICT in- } \\
\text { frastructure for responsible actors }\end{array}$ \\
\hline \multicolumn{2}{|c|}{ Quality of electricity: } \\
\hline \multirow{3}{*}{$\begin{array}{l}\text { Applied knowledge about technical speci- } \\
\text { fications of ICT equipment (e.g. voltage } \\
\text { ranges), physics (e.g. thermal expansion), } \\
\text { electrochemistry (e.g. galvanic corrosion), } \\
\text { and electrical wiring (e.g. grounding prin- } \\
\text { ciples) }\end{array}$} & $\begin{array}{l}\text { To measure characteristics of electric power such } \\
\text { as voltage level and ground resistance }\end{array}$ \\
\hline & $\begin{array}{l}\text { To estimate sufficiency of an electric power sys- } \\
\text { tem for power consumption }\end{array}$ \\
\hline & $\begin{array}{l}\text { To advice responsible actors when an electric } \\
\text { power system might threaten ICT services }\end{array}$ \\
\hline \multicolumn{2}{|c|}{ Local area network: } \\
\hline Installation requirements of LAN wiring & $\begin{array}{l}\text { To design and construct ICT infrastructure appro- } \\
\text { priately for its context of use }\end{array}$ \\
\hline & To maintain ICT services in line with organiza- \\
\hline $\begin{array}{l}\text { Applied knowledge about physics and } \\
\text { electrochemistry }\end{array}$ & tional goals \\
\hline
\end{tabular}




\begin{tabular}{|l|l|}
\hline Knowledge areas & Corresponding skills \\
\hline $\begin{array}{l}\text { Technical specifications and standards } \\
\text { Quality requirements }\end{array}$ & $\begin{array}{l}\text { Peripherals: } \\
\text { To analyze and measure characteristics of electri- } \\
\text { cal circuits of ICT equipment } \\
\text { To protect ICT infrastructure against inappropri- } \\
\text { ate use of peripherals and possible vulnerabilities } \\
\text { arising from low quality products }\end{array}$ \\
& $\begin{array}{l}\text { ICT users: } \\
\text { Organizational requirements } \\
\text { Principles of ergonomics } \\
\text { ICTs appropriateness for the users }\end{array}$ \\
& $\begin{array}{l}\text { To identify and define organizational require- } \\
\text { ments for ICT services } \\
\text { To merge requirements of organization and ICT } \\
\text { To maintain and improve ICT infrastructure con- } \\
\text { tinuously in line with organizational goals }\end{array}$ \\
\hline
\end{tabular}

ITSM education in Tanzania should provide students deep understanding about the sensitivity of ICT equipment to various environmental factors. IT graduates should understand possible effects of local climate conditions, UV radiation, and other environmental factors. In addition, they should be able to protect ICT installations against those threats. Such knowledge creates a solid foundation for locally valuable ICT expertise.

Arrangements concerning physical security play a central role in protecting ICT equipment against crime. ITSM professionals should be able to analyze possible threats to ICT services derived from security arrangements and recommend alternative solutions when appropriate. Even though organizational security procedures are important, they are rarely adequate against internal threats. This means that IT professionals should understand and be able to utilize opportunities that local cultural values, such as communalism, offer for security arrangements.

Characteristics of premises and rooms that affect the construction, usage, maintenance, and lifetime of ICT infrastructure play an important role in the availability of ICT services. In Tanzania, proper ventilation arrangements and installation requirements of ICT equipment are often ignored when new buildings are constructed. Similarly, when rooms are reallocated, requirements of ICT equipment, such as air circulation needs, are rarely noted.

It is hard to overemphasize the threats that power problems in developing countries pose to ICT infrastructure. The operation of ICT infrastructure depends on reliable power supply and this dependency indicates that IT graduates must reach significant expertise in power protection. IT professionals should be able to estimate the quality of electrical wiring on the site, as well as its sufficiency related to total power consumption. What is more, students cannot reach this level of expertise without appropriate knowledge in chemistry and physics.

LAN wiring and electrical wiring give rise to a number of similar challenges. For example, IT graduates should be able to prepare and evaluate tenders for procuring new material or equipment. These skills are required mainly due to widely spread counterfeit products, but suppliers' capacity to fulfill orders should be noted too. In addition, as mentioned earlier, the threat of harmful insects and small animals to wirings should be carefully considered during the design phase. 
ICT security requires broader understanding from IT professionals in developing countries than it does from IT professionals in developed ones. The security threats are similar, but specialized support is rarely available in developing countries. This means that IT professionals should be able to develop alternative ways to localize generally used practices, such as centralized download procedures of security updates, for minimizing threats.

Carelessly used peripherals create significant risks to other ICT equipment. This challenge is often related to pirate product manufacturers' neglect of the industry standards. In addition, peripherals are sometimes misused due to users' lack of ICT knowledge. Therefore, it is vital that graduates are able to advise and educate organization's ICT users about a number of basic technical topics.

Based on the above-described characteristics of IT work in Tanzania, we argue that IT professionals cannot successfully design, construct, or maintain ICT services of organizations in Tanzania without a deep understanding about the technical topics presented above. This means that weaknesses of IT education in the presented knowledge areas hinder graduates' capability to guarantee self-sustainability of constructed ICT services. Those knowledge areas - summarized in Table 1-should be taken into account in designing the local relevance of ITSM curriculum.

As a summary of Table 1, the following list presents the corresponding capabilities and competencies for ITSM graduates:

- Climate conditions on the site - To protect ICT equipment against environmental factors

- Physical security on the site - To estimate security arrangements of institution and advice improvements when necessary

- Characteristics of premises - To apply understanding about drawings and electrical diagrams of premises in practice when managing ICT infrastructure

- Characteristics of rooms - To comply with specifications of ICT equipment in practical circumstances

- Quality of electricity - To guarantee continuity of ICT services in spite of power problems

- Local area network - To evaluate appropriate alternatives when designing and maintaining local area network

- Peripherals - To analyze peripherals' effects to other parts of ICT infrastructure and to implement appropriate preventive actions

- $\quad$ ICT users - To design and maintain ICT services that fit for their purpose of use.

\section{Discussion}

Our view of IT education in Tanzania differs slightly from Heeks's vision (2008, p. 31) on ICT4D champions. Heeks proposed that ICT4D champions should gain enough understanding on the fields of computer science, information systems, and development studies. We agree with him that development studies should be a vital part in IT education of developing countries because a number of the characteristics of IT work in Table 1 derives from the local socio-cultural setting. The weakness in Heeks's vision is that studies in computer science and information systems do not prepare IT graduates to overcome the technical challenges that IT professionals in developing countries frequently meet. In addition, the focus of the typical IT curriculum (Figure 3, adapted from ACM/IEEE-CS, 2008) strongly emphasizes the recognition of organizational needs and ICT users' needs (ACM/IEEE-CS, 2008, p. 17). According to the ACM/IEEE IT curriculum 2008, IT education has to cover appropriate topics of organizational issues and information systems, application technologies, software methods and technologies, and system infrastructure. This means that an appropriately designed IT curriculum always contains information systems and computer science perspectives. 


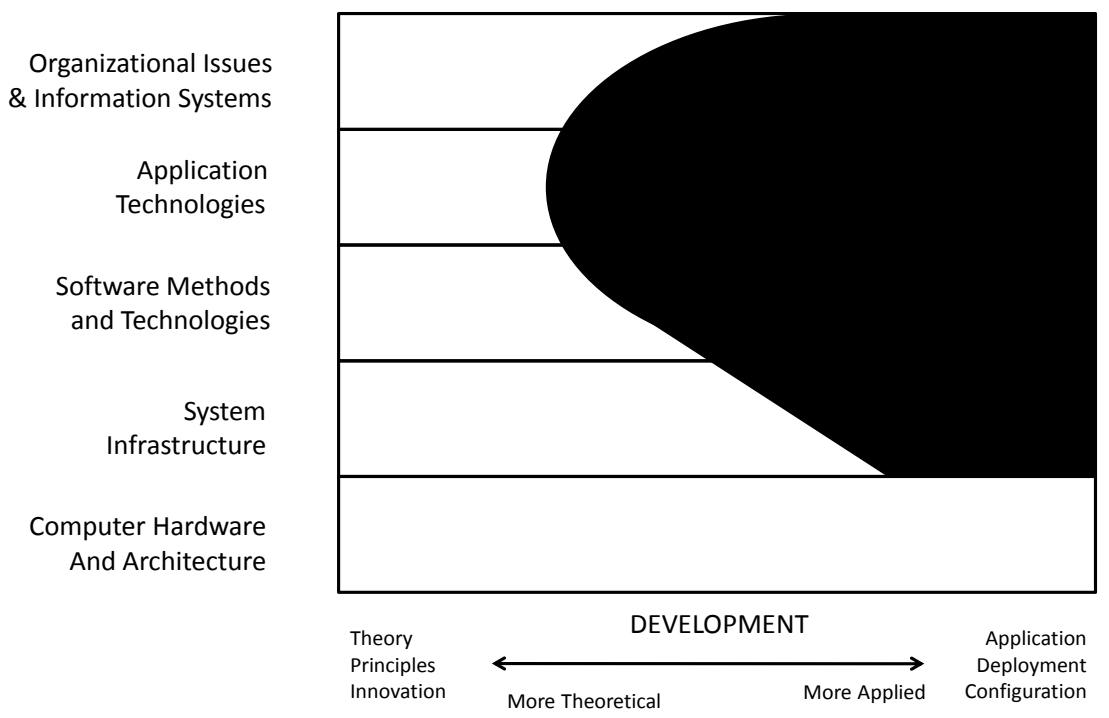

Figure 3: The problem base of information technology

A comparison between the focus of ACM/IEEE IT curriculum 2008 recommendations (Figure 3) and the list of requirements presented in Table 1 shows an obvious gap in what is required from IT professionals in developed and developing countries. IT professionals in developing countries need broad understanding of environmental effects, physical security, power-related issues, and characteristics of premises for ICT equipment. Without basic understanding about those issues, it is impossible for them to maintain the level of ICT services on a sufficient level. The topics presented in Table 1 belong to the fields of electrical and civil engineering in the developed countries' educational system. Still, local relevance of IT education in developing countries requires integration of those topics in the IT curriculum. This is necessary for fulfilling ICT requirements of organizations and ICT users in developing regions. The situation is different in developed countries where other professionals manage many of those topics before the IT professionals' work begins.

The integration of the rather practical skills in Table 1 in ITSM degree program requires, firstly, that IT curriculum designers know global requirements for IT graduates' expertise and, secondly, that they should be able to combine those requirements with the locally appropriate skills. Both of those perspectives are vital in ITSM curriculum design because academic programs do prepare students for scientific goals, but they often also aim at a particular field or a job. Figure 4 describes our recommendation for extension of IT curriculum 2008 for ITSM studies. IT curriculum designers should carefully consider the aspects of their own local context and expand their ITSM education by appropriate topics from other fields - electrical engineering, civil engineering, and development studies in this case. In addition, we argue that because of ITSM education's inherent orientation towards a practical skill set, a real-life learning environment is essential. This is because the development of students' expertise requires a heavy emphasis on practical training through problem orientation. 


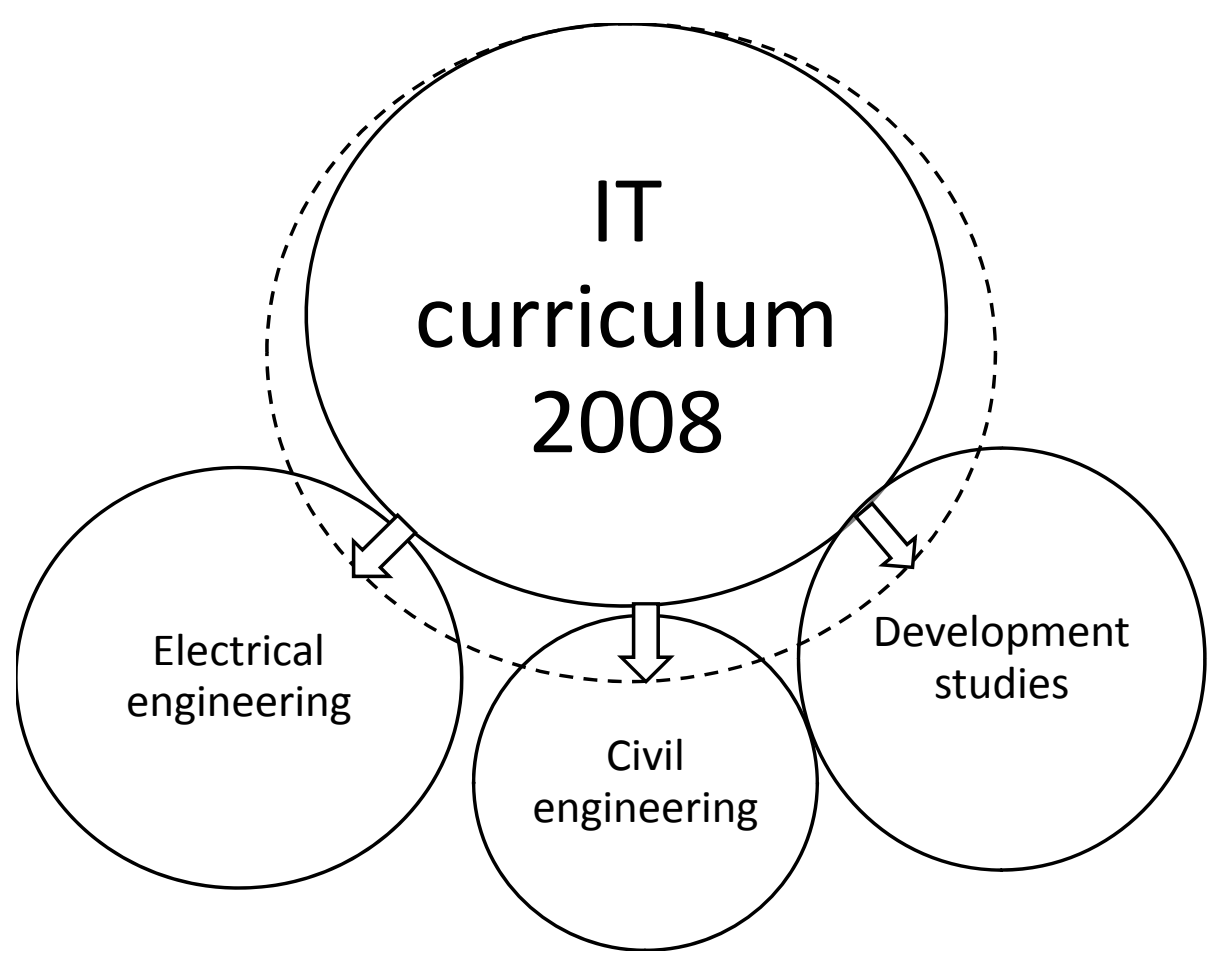

Figure 4: Recommended extension for IT curriculum 2008 for the needs of ITSM education in developing countries.

In addition to technical topics, our analysis indicates that organizational support plays a central role in self-sustainability of ICT services. This indicates that contextually relevant advocacy work within institutions is a vital part of IT professionals' work. For ITSM education this means that the role of management and leadership skills should be recognized in a culturally sensitive way in ITSM curriculum design. In addition, international frameworks for ITSM (such as ITIL) emphasize a structured and well-organized approach for guaranteeing the quality of ICT services (Adams et al., 2009). The capacity to fulfill such requirements is a challenge per se and demands strong commitment to IT professionalism. These three nontechnical characteristics of IT professional's work - management, leadership, and professionalism—play important roles in the quality of ITSM. The educational content of these characteristics should have strong foundation in local culture.

\section{Conclusions}

The literature shows that IT work in developing countries differs from IT work in developed countries. In addition, in East Africa there is a scarcity of capable IT professionals who can effectively manage IT systems on various scales. Based on the literature and our fourteen years of fieldwork in Iringa, Tanzania, we presented eight groups of technical characteristics of IT work that significantly affect the work of IT professionals in this particular developing country context. Those groups are climate conditions on the site, physical security on the site, characteristics of premises, characteristics of rooms, quality of electricity, local area network, peripherals, and ICT users. Even though the presented characteristics of IT work are a challenge for IT professionals, they can be overcome with appropriate education and preparation.

We showed that IT professionals are hardly prepared for maintaining ICT services of organizations on a sufficient level without a broad understanding about environmental effects, physical security, power-related issues, and characteristics of premises for ICT equipment. The solutions to the practical challenges in the Tanzanian context leads us to a conclusion that ITSM education 
in developing countries must include some topics from the fields of electrical engineering and civil engineering in the IT curriculum. The selection of those topics should be based on an analysis of local situation. Therefore, the topics might be valid in a certain context only. Still, they should not be ignored, because local appropriateness of ITSM education depends on them.

Properly designed ITSM education requires that locally appropriate IT skill set is integrated in global requirements for IT graduates' expertise. Local and global perspectives are vital aspects in ITSM curriculum design, because academic programs do not only prepare students for a particular job in a specific context as, for example, vocational training does, but they prepare students for academic learning and further education, too. Therefore, IT curriculum designers should carefully consider the aspects of their own local context and expand their ITSM curriculum by appropriate topics from various other fields. Inclusion of locally needed topics in education prepares students to overcome common challenges particular to their future working milieu.

In addition to technical skills, our research indicates that when aiming at sustainable ICT services, IT professionals should be able to advocate other members of their organization. This is because organizational support for IT work plays a central role in self-sustainability of ICT services. Therefore, ITSM education has to recognize this issue in curriculum design. Even though further studies are required before detailed recommendations, in the light of our current understanding we propose an approach where good management and leadership skills are taught in a culturally sensitive way. In addition, rapidly developing ICT requires that lifelong learning is an integral part of ITSM graduates’ professional identity.

\section{Acknowledgments}

This research was funded by the Academy of Finland grants \#128577 and \#132572.

\section{References}

Adams, S., Cartlidge, A., Hanna, A., Rance, S., Sowerby, J. and Windebank, J. (2009). ITIL V3 Foundation Handbook ( ${ }^{\text {nd }}$ ed.). London, England: The Stationery Office.

Akubue, A. (2000) Appropriate technology for socioeconomic development in third world countries. The Journal of Technology Studies, XXVI (1), 33-43.

Association for Computing Machinery, Association for Information Systems, and IEEE Computer Society. (2005). The overview report. Retrieved February 15, 2012, from http://www.acm.org//education/curricula/IT2008n\%20Curriculum.pdf

Association for Computing Machinery, and IEEE Computer Society. (2008). Information technology 2008. Retrieved February 15, 2012, from http://www.acm.org//education/curricula/IT2008n\%20Curriculum.pdf

Bass, J., \& Heeks, R. (2011). Changing computing curricula in African universities: Evaluating progress and challenges via design-reality gap analysis. The Electronic Journal on Information Systems in Developing Countries, 48(5), 1-29.

Bon, J., Pieper, M., \& Veen, A. (Eds.). (2006). Foundations of IT service management based on ITIL (2nd ed.). ITSMF-NL: Van Haren Publishing.

Brewer, E., Demmer, M., Ho, M., Honicky, R., Pal, J., Plauche, M., et al. (2006). The challenges of technology research for developing regions. Pervasive Computing, 5(2), 15-23.

Coate, K. (2009). Curriculum. In M. Tight, K. Mok, J. Huisman, \& C. Morphew (Eds.), The Routledge international handbook of higher education (pp. 77-89). Routledge.

Farrant, J. (1981). Principles and practice in education (2nd ed.). Harlow, UK: Pearson Education Limited, Longman. 
Hazeltine, B., \& Bull, C. (1998). Appropriate technology: Tools, choices, and implications. Orlando: Academic Press Inc.

Heeks, R. (2008). ICT4D 2.0: The next phase of applying ICT for international development. Computer, 41(6), 26-33.

Hyvönen, P. (2008). Prediction of insulation degradation of distribution power cables base on chemical analysis and electrical measurements. Doctoral Dissertation, Helsinki University of Technology.

International Telecommunication Union. (2010). World Telecommunication/ICT Development Report 2010. A mid-term review. Retrieved February 23, 2012, from http://www.itu.int/ITUD/ict/material/FactsFigures2010.pdf

Iringa University College/Tumaini University [IUCo]. (2004). Internet project strategic plan project file 2001-2004. Technical Report. Tumaini University, Iringa, Tanzania.

Iringa University College/Tumaini University [IUCo]. (2008). Library facilities improvement project file 2000-2008. Technical Report. Tumaini University, Iringa, Tanzania.

Kamppuri, M. (2011). Theoretical and methodological challenges of cross-cultural interaction design. Doctoral Dissertation, University of Eastern Finland.

Kemppainen, J. (2006). Building ICT facilities for education in a developing country. Analysis of an ICT project at Tumaini university/Iringa university college 2000-2004. Master's thesis, University of Joensuu.

Kitchens, F. (2006). High performance computing as an educational experience well suited to developing nations. Fourth IEEE International Workshop on Technology for Education in Developing Countries (pp. 38-43). IEEE Computer Society.

Machonachy, V., Shou, C., Ragsdale, D., \& Welch, D. (2001). A model for information assurance: An integrated approach. Proceedings of the 2001 IEEE Workshop on Information Assurance and Security. New York: United States Military Academy, West Point.

North Eastern Diocese of Evangelical Lutheran Church in Tanzania (NED-ELCT). (2008). Kilindi Council Designated Hospital Constructions project plans. The project's drawings 2008. The Finnish Evangelical Lutheran Mission's archive.

Prospects. (2011). The UK’s official graduate career website. Retrieved October 4, 2011, from http://www.prospects.ac.uk/architect_job_description.htm

Sachs, J. (2005). The end of poverty. London: Penguin Books.

Smillie, I. (2008). Mastering the machine revisited (2nd ed.). Warwickshire: Practical Action Publishing.

Surana, S., Patra, R., Nedevschi, S., Ramos, M., Subramanian, L., Ben-David, Y., et al. (2008). Beyond pilots: Keeping rural wireless network alive. Proceedings of the 5th USENIX Symposium on Networked Systems Design and Implementation. Berkeley: USENIX Association.

Swantz, M-L. (1989). Transfer of technology as an intercultural process. Helsinki: Finnish Anthropological Society.

Tedre, M., Apiola, M., \& Cronje, J. (2011). Towards a systemic view of educational technology in developing regions. Proceedings of IEEE Africon 2011 Conference.

Tedre, M., Bangu, N., \& Nyagava, S. (2009). Contextualized IT education in Tanzania: Beyond standard it curricula. Journal of Information Technology Education, 8, 101-124. Retrieved from http://www.jite.org/documents/Vol8/JITEv8p101-124Tedre440.pdf

Tedre, M., Kemppainen, J., \& Ngumbuke, F. (2011). What foreign it experts should know about it work in developing countries. Proceedings of IST-Africa 2011 Conference.

Torero, M., \& Braun, J. (Eds.). (2006). Information and communication technologies for development and poverty reduction. International Food Policy Research Institute. Baltimore: The Johns Hopkins University Press. 
The United Republic of Tanzania, Planning Commission. (1999). The Tanzania development vision 2025. Retrieved February 15, 2012, from http://www.tanzania.go.tz/vision.htm

United Nations Development Programme (UNDP). (2010). Human development report 2010. Retrieved February 21, 2012, from http://hdr.undp.org/en/media/HDR 2010_EN_Complete_reprint.pdf

Vesisenaho, M. (2007). Developing university-level introductory ICT education in Tanzania: A contextual approach. Doctoral Dissertation, University of Joensuu.

The World Bank Task Force on Higher Education and Society. (2000). Higher education in developing countries: Peril and promise. The World Bank, The United Nations Educational, Scientific and Cultural Organization, and The International Bank for Reconstruction and Development. Retrieved February 15, 2012, from http://www.accesstosuccess-africa.eu/web/images/literature/peril_and_promise.pdf

\section{Biographies}

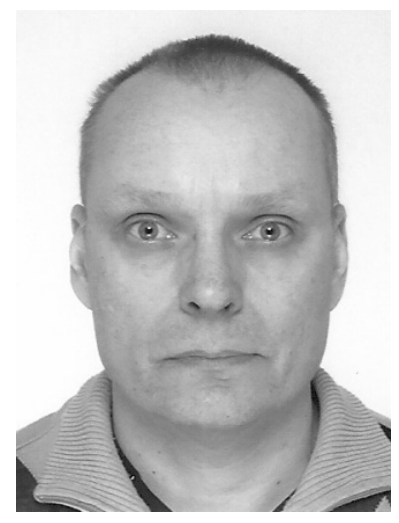

Jyri Kemppainen is a junior researcher in School of Computing at the University of Eastern Finland, Joensuu. His interests center on ICT for development, IT service management, and IT service management education in developing countries. He has more than 25 years working experience in various IT positions in organizations.

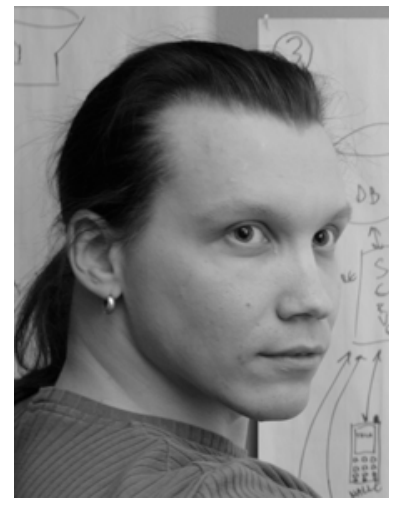

Matti Tedre is a professor in the B.Sc. Program in IT at Tumaini University, Iringa, Tanzania; a senior lecturer at Department of Computer and Systems Sciences, Stockholm University, Sweden; and an adjunct professor of Informatics and Design in Cape Peninsula University of Technology, South Africa and of Computer Science at University of Eastern Finland. Currently he is working for a research project called 'Technological and Pedagogical Development of Contextualized IT Education.

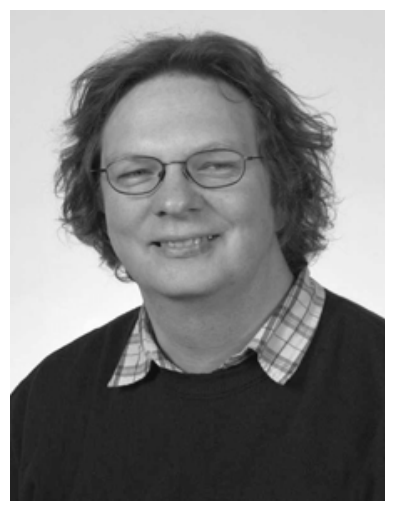

Erkki Sutinen is a professor of Computer Science at the University of Eastern Finland, Joensuu. His research interests includes IT education in developing countries, the development of learning tools such as visualization and digital portfolios, the influence of cultural factors in educational technology, computer science education, and information retrieval/string algorithms. 